\title{
CHRONIC JOB INSECURITY AMONG AUTOMOBILE WORKERS: EFFECTS ON JOB SATISFACTION AND HEALTH
}

\author{
Catherine A. Heaney, ${ }^{1}$ Barbara A. Israel ${ }^{2}$ and James S. House ${ }^{3}$ \\ ${ }^{1}$ The Ohio State University, Department of Preventive Medicine, 320 W. 10th Avenue, Columbus, OH \\ 43210-1240, U.S.A., ${ }^{2}$ University of Michigan, School of Public Health, Department of Health Behavior \\ and Health Education, 1420 Washington Heights, Ann Arbor, MI 48109, U.S.A. and ${ }^{3}$ University of \\ Michigan, Institute for Social Research, Departments of Sociology and Epidemiology, Ann Arbor, \\ MI 48106, U.S.A.
}

\begin{abstract}
Work conditions characterized by uncertainty and ambiguity are potential stressors for employees. One such stressor is job insecurity. This longitudinal study of 207 automobile manufacturing workers indicates that chronic job insecurity is predictive of changes over time in both job satisfaction and physical symptoms. Extended periods of job insecurity decrease job satisfaction and increase physical symptomatology, over and above the effects of job insecurity at any single point in time. These results indicate that job insecurity acts as a chronic stressor whose effects become more potent as the time of exposurc increases. Worksite health professionals should devclop strategics for reducing the impact of job insecurity on employee well-being, particularly in industries where employment opportunities are declining.
\end{abstract}

Key words-job insecurity, chronic stress, job satisfaction, employee health

\section{INTRODUCTION}

Psychological and social stresses in the workplace have been established as risk factors for a host of both mental and physical health problems [1-5]. In addition to the accumulation of epidemiological evidence, biomedical research has suggested neurological and immunological mechanisms for the deleterious effects of psychosocial stress on health [6]. According to estimates based on the 1985 National Health Interview Survey, 11 million American workers felt that exposure to mental stress at work endangered their health [7]. The costs of stress-related symptoms in terms of absenteeism, lost productivity and company health care expenses have been estimated at $\$ 50$ billion annually [8].

Work conditions characterized by uncertainty and ambiguity are potential stressors or causes of stress for employecs $[9,10]$. Onc such stressor is job insecurity. Job insecurity, defined as an employee's perception of a potential threat to continuity in his or her current job, should be differentiated from actual job loss and unemployment. Whereas the stressful aspects of job loss include financial concerns and interruptions in one's usual role tasks and obligations, the stressful aspects of job insecurity stem from anticipating the problems of job loss, ambiguity about what the future holds and, thus, lack of clarity as to which responses might be most adaptive [11]. Job insecurity is especially prevalent among employees in industries that are downsizing and closing facilities, and especially stressful for those employees who will be least able to find other comparable jobs if they lose their current positions [12]. Thus, job insecurity is a particularly potent stressor in manufacturing industries that have undergone substantial downsizing in the past decade and for which unions have successfully negotiated strong wage and benefit packages [13].

Job insecurity has not received as much attention in the occupational stress literature as other psychosocial stressors. Several cross-sectional studies have shown that employees who perceive that they have an uncertain future in their jobs often feel threatened and anxious, and may exhibit symptoms of distress such as depression and somaticization $[5,12,13]$. Prospective studies support these findings, as illustrated by the following examples. Shipyard workers threatened with job loss had significantly higher scores for sleep disturbance, depression, anxiety and serum cholesterol than other workers [14]. Absenteeism was elevated in railwaymen threatened with loss of their jobs [15]. Psychiatric symptoms were elevated among newspaper workers who anticipated that their jobs would be terminated. These symptoms abated once thcir jobs were secured [16]. In a study of a plant closing, the mean number of days when physical symptoms were experienced was higher for those employees who anticipated losing their jobs than for those employees in a control group [17].

However, little is known about whether such effects depend on the chronicity of job insecurity. Conceptual models of stress suggest that persistent high levels of stress are more likely to result in illness than 
are variable levels of stress. As stressors continue unabated, they may overwhelm an individual's available resources to cope with or adapt to the stressor [18]. Thus, individuals may be likely to experience various short-term adverse responses to stress, including emotional (anxiety, tension, dissatisfaction), physiological (clevated heart ratc, incrcased catecholamine secretion) and behavioral (drug use, absenteeism, lack of concentration) responses. If allowed to persist, these responses are likely to result in longterm adverse health consequences [3]. Indeed, in an investigation of occupational stress in a community sample, although reports of high levels of job stress at one point in time did not predict subsequent mortality, chronic high levels of job tensions and pressures (measured at two points in time approximately two years apart) did contribute to premature mortality [19]. A study that explored the effects of job insecurity and unemployment among blue-collar workers over a 2-yr period found that the adverse effects of unemployment abated over the course of the study, but that the mental well-being of employees in insecure jobs worsened. More specifically, the average mental well-being of employees in insecure jobs was not lower than that of a comparison group of employees in secure jobs until a year of job insecurity had been experienced. Whereas workers appeared to adapt to the stresses of unemployment, there seemed to be a cumulative effect of chronic job insecurity [20].

The present study examines the effects of job insecurity among employees in an automobile manufacturing plant in a mid-sized city in the United States. Figure 1 presents the conceptual framework for the study. Data from two points in time are utilized. It is hypothesized that Time 2 strains will be determined through different pathways. First, the strain is expected to show some stability over time. Thus, Time 1 strain will be positively related to Time 2 strain. Second, job insecurity measured at the same

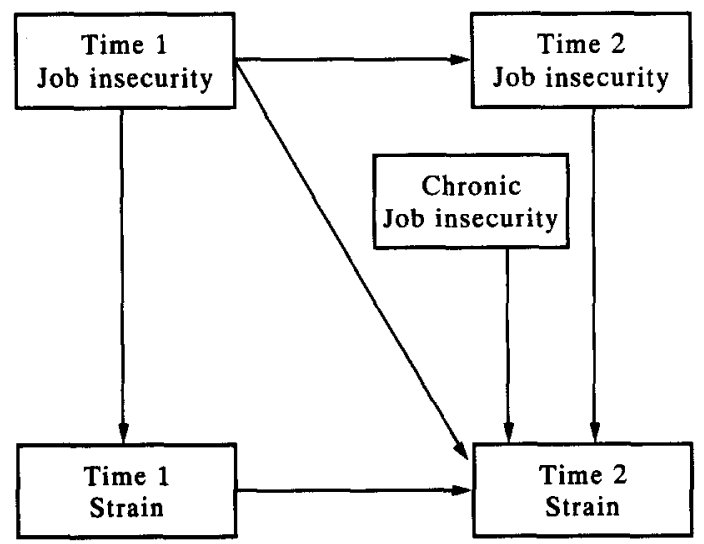

Fig. 1. Pathways through which job insecurity may affect strains over time. Note: a complete rendering of the stress process includes feedback loops that allow levels of strain to influence levels of stressors (e.g. job insecurity). For the sake of clarity, these feedback loops are not shown. time as the Time 2 strain will be related to greater strain. Third, Time 1 job insecurity can be related to Time 2 strain through its relationship with the Time 1 strain and Time 2 job insecurity. In addition, Time 1 job insecurity may have a direct, lagged effect on Time 2 strain. In other words, the effect of job insecurity may be delayed. Lastly, having high job insecurity at both points in time (i.e. chronic job insecurity) may have a synergistic effect on Time 2 strain, over and above the additive effects of the Time 1 and Time 2 measures of job insecurity.

The strains that are investigated in this study are lack of job satisfaction and physical symptoms. These two outcomes were chosen because they are hypothesized to exhibit different relationships with the job insecurity stressor over time. Job satisfaction, employees' affective reactions to their jobs based on how well actual experiences and rewards compare with desired or expected experiences or rewards, is expected to be relatively immediately affected by job insecurity. The effect of job insecurity on physical health is expected to increase as the cxposure to the unabated stressor continues over time.

\section{METHODS}

\section{Data collection and sample}

A plantwide survey was conducted in April 1986 and again in June 1987. The survey was self-administered during regular work hours, with participation being voluntary. Questionnaires assessed physical and mental health, as well as many work-related factors such as stressors, the quality of work relationships, participation and influence in decision-making and health behaviors.

The response rates for the two surveys were 61 and $41 \%$, respectively, resulting in a panel sample of 207 employees. Attrition from the sample is diagrammed in Fig. 2. Due to the automobile manufacturing downturn in business and the reduction of product lines that were previously housed in this factory, approx. $25 \%$ of the Wave 1 sample was no longer employed in the plant at Wave 2 . In addition, the downturn in business affected some employees' morale and willingness to participate in activities jointly sponsored by union and management. Two hundred and fifty-one employees who responded at Wave 1 chose not to respond to Wave 2.

Subgroup analyses were conducted in order to characterize any differences between responders, those who left the plant between the two survey administrations, and the non-responders at Wave 2 . As expected, the 169 employees who were no longer in the plant at Wave 2 were younger, had less seniority in the company and reported having the less challenging jobs in the plant. These were the employees who were most likely to be laid off from their jobs. The 251 non-responders at Wave 2 tended to be slightly less educated, older and to have higher 


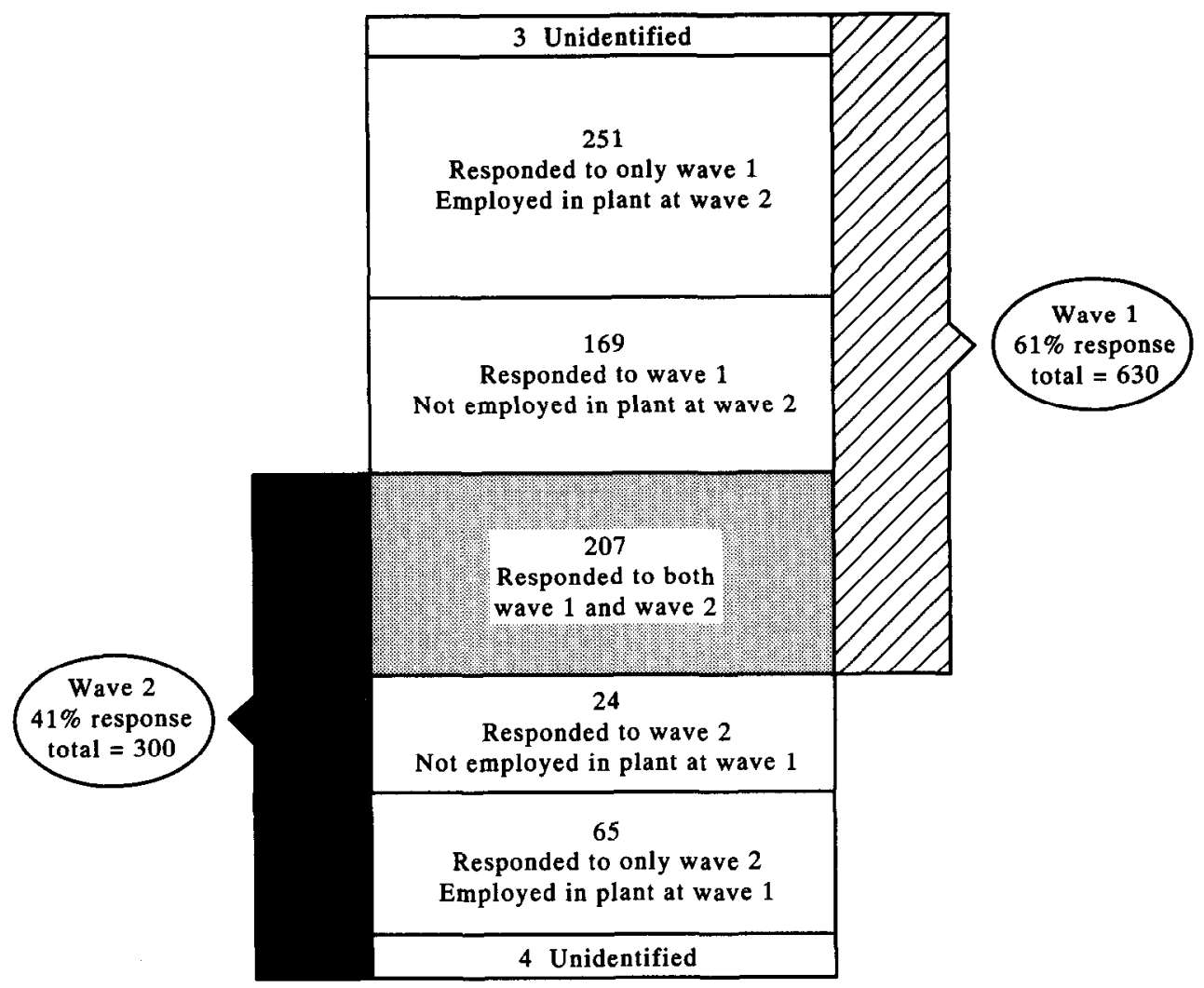

Fig. 2. Attrition from the sample.

seniority than the panel sample. In order to examine potential significant differences between the panel sample and the 251 who chose not to participate at Wave 2, extensive comparisons were made on such variables as perceived stresses, levels of social support, extent of participation and influence in decision-making, job satisfaction and health outcomes. Of the more than 100 comparisons analyzed, only three showed significant differences between the two groups. Thus, besides the demographic differences noted above, the non-response at Wave 2 appears to be due to factors unrelated to the variables under study.

The demographics of the panel sample were comparable to those of the overall plant population. The sample was predominantly male $(92 \%)$, married $(82 \%)$ and white $(84 \%)$. Employees ranged in age from 20 to 62 years, with the mean age being 41 years $(\mathrm{SD}=7.9)$. Eleven percent of the sample reported not graduating from high school, and $>50 \%$ attended some educational institution after high school (e.g. trade school or college). The sample was composed of $78 \%$ hourly, unionized employees and $22 \%$ salaried employees. Salaried employees were slightly overrepresented in the sample.

\section{Measures}

Measures of the study variables were adapted from previously validated multi-item scales $[1,4]$. Job security was measured by a five-item index that incorporated respondents' perceptions of the extent to which their jobs were secure, the likelihood that they would be laid off and the threat to their jobs from recent changes in the industry (Cronbach alpha $=0.74$ ). A six-item scale measured job satisfaction. This scale included items to assess overall satisfaction with the job, the likelihood that employees would advise friends to accept jobs similar to their own, the likelihood that employees would currently decide to take their jobs if given the choice, and the extent to which employees felt happy and proud about their work (Cronbach alpha $=0.84$ ). Physical symptomatology was assessed by an index of 17 somatic symptoms. Employees reported how often they experienced each symptom during the past few months $(1=$ Hardly Ever, $2=$ Some of the Time, $3=$ Most of the Time). Symptoms included: shortness of breath or trouble breathing; chest tightness, pressure and pain; 'racing' or pounding heart; frequent colds or sore throats; persistent cough; cramps or pain in the hands, wrists, arms, back and legs; eye strain and eye irritation; ringing in ears; difficulty hearing; skin irritation; and frequent headaches (Cronbach alpha $=0.84$ ).

\section{Data analysis}

In order to operationalize chronic job insecurity, the Time 1 and Time 2 measures of job insecurity 
were trichotomized into low, medium and high categories. Those employees who reported high levels of job insecurity at both points in time $(n=44)$ were designated as employees with chronic high job insecurity. The effects of job insecurity on job satisfaction and physical symptomatology were explored using hierarchical OLS regression analyses. In the first model, the control variables (age, education, race and job class) and the Time 1 strain were included as independent variables. The inclusion of the Time 1 strain variables allows us to assess change in the strain over time. Time 1 and Time 2 job insecurity were added in Steps 2 and 3, respectively. To specifically test the hypothesis that chronic high levels of job insecurity have adverse effects over and above the additive effects, a dummy variable was created ( $1=$ Chronic high job insecurity, $0=$ Variable or low job insecurity) and entered in the last step.

\section{RESULTS}

Descriptive statistics for the study variables at Time 1 and Time 2 are presented in Table 1. Mean levels of job insecurity increased and mean lcvels of job satisfaction decreased during the time of the study. Table 2 presents the zero order correlations between the study variables. The cross-sectional relationships between job insecurity and the two study outcomes were very similar at both data collection points. The correlation between job insecurity and job satisfaction at Time 1 was -0.34 and at Time 2 was -0.33 . The correlation between job insecurity and physical symptomatology was 0.30 and 0.31 at the two points in time.

Table 3 presents the regression results for job satisfaction. Time 1 job satisfaction is a strong predictor of Time 2 job satisfaction throughout all of the steps in the model. The addition of Time 1 job insecurity explained a significant amount of the variance in job satisfaction $\left(\Delta R^{2}=0.03, P<0.01\right)$. When Time 2 job insecurity was added in Step 3, its regression coefficient was significant and the coefficient for Time 1 job insecurity became nonsignificant. This indicates that the effect of Time 1 job insecurity on job satisfaction was not a direct lagged effect, but rather was mediated through Time 2 job insecurity. The inclusion of the chronic job insecurity
Table 1. Descriptive statistics for job insecurity, job satisfaction, and physical symptomatology

\begin{tabular}{lccccc}
\hline & \multicolumn{2}{c}{ April } & 1986 & & \multicolumn{2}{c}{ June 1987} \\
\cline { 2 - 3 } \cline { 5 - 6 } Variable and (range) & Mean & SD & & Mean & SD \\
\hline Job insecurity (1-5) & 3.07 & 0.95 & & 3.32 & 0.99 \\
Job satisfaction (1-5) & 3.95 & 0.96 & & 3.68 & 0.99 \\
Physical symptoms (1-3) & 1.34 & 0.28 & & 1.35 & 0.30 \\
\hline
\end{tabular}

dummy variable in Step 4 added significantly to the model $\left(\Delta R^{2}=0.03, P<0.01\right)$.

Table 4 presents the regression results for physical symptoms. The large coefficients for Time 1 symptoms illustrates the stability of symptoms over time. The addition of Time 1 job insecurity added $2 \%$ to the explained variance in Time 2 symptoms. Similar to the patterns found for job satisfaction, the addition of Time 2 job insecurity in Step 3 caused the coefficient for Time 1 job insecurity to diminish. However, Time 2 job insecurity was not a significant predictor of changes in physical symptoms. Chronic high job insecurity was significantly related to increases in physical symptoms $\left(\Delta R^{2}=0.02, P<0.01\right)$.

A full conceptualization of the stress process allows for feedback loops, i.e. high levels of strain may act to increase stress levels. Thus, we explored the effect of physical symptoms and job satisfaction on job insecurity. To do this, we regressed job insecurity on Time 1, Time 2 and chronic levels of job satisfaction and physical symptoms using the same hierarchical approach described above. Neither Time 1, Time 2 nor chronic levels of physical symptoms were significantly related to job insecurity. Neither Time 1 job satisfaction nor chronic low job satisfaction had an effect on job insecurity. There was a significant relationship between Time 2 job satisfaction and job insecurity $(\beta=-0.18, P<0.01)$. Except for this cross-sectional relationship, the relationships between job insecurity and these two strains do not appear to be reciprocal in nature for the employees in this study.

\section{DISCUSSION}

The results of this study largely supported our hypotheses. Job insecurity was predictive of changes over time in both job satisfaction and physical symptoms. For job satisfaction, both a high Time 2 level

Table 2. Correlation matrix of study variables"

\begin{tabular}{|c|c|c|c|c|c|c|c|}
\hline & 1 & 2 & 3 & 4 & 5 & 6 & 7 \\
\hline 1. Age & $(1.0)$ & -0.40 & -0.03 & 0.31 & 0.13 & 0.09 & 0.04 \\
\hline 2. Education & -0.39 & $(0.90)$ & 0.06 & -0.46 & -0.15 & -0.08 & -0.17 \\
\hline 3. Race $^{\mathrm{b}}$ & 0.01 & 0.07 & $(1.0)$ & 0.07 & -0.05 & 0.01 & 0.10 \\
\hline 4. Job class ${ }^{\mathfrak{c}}$ & 0.34 & -0.48 & 0.11 & $(1.0)$ & 0.14 & 0.20 & 0.29 \\
\hline 5. Job satisfaction & -0.05 & -0.14 & 0.03 & 0.02 & $(0.58)$ & -0.26 & -0.33 \\
\hline 6. Physical symptoms & 0.09 & -0.05 & -0.04 & 0.17 & -0.38 & $(0.75)$ & 0.31 \\
\hline 7. Job insecurity & 0.06 & -0.27 & 0.15 & 0.45 & -0.34 & 0.30 & $(0.70)$ \\
\hline
\end{tabular}


Table 3. Heirarchical regression models of the effects of job insecurity on Time 2 job satisfaction ${ }^{\mathrm{a}}$

\begin{tabular}{|c|c|c|c|c|}
\hline $\begin{array}{l}\text { Independent } \\
\text { variables }\end{array}$ & $\begin{array}{c}\text { Step } \\
1\end{array}$ & $\begin{array}{c}\text { Step } \\
2\end{array}$ & $\begin{array}{c}\text { Step } \\
3\end{array}$ & $\begin{array}{c}\text { Step } \\
4\end{array}$ \\
\hline Age & $0.14^{*}$ & 0.11 & 0.11 & 0.11 \\
\hline Education & 0.05 & 0.01 & 0.00 & 0.07 \\
\hline Race $^{\mathrm{b}}$ & 0.07 & -0.04 & -0.04 & -0.06 \\
\hline Job class ${ }^{c}$ & 0.11 & $0.19^{*}$ & $0.18^{*}$ & $0.20^{* *}$ \\
\hline $\begin{array}{l}\text { Time } 1 \\
\text { Job Satisfaction }\end{array}$ & $0.61^{* * *}$ & $0.53^{* * *}$ & $0.52 * * *$ & $0.55^{* * *}$ \\
\hline $\begin{array}{l}\text { Time } 1 \\
\text { Job Insecurity }\end{array}$ & & $-0.19^{* *}$ & 0.05 & 0.15 \\
\hline $\begin{array}{l}\text { Time } 2 \\
\text { Job Insecurity }\end{array}$ & & & $-0.22^{* *}$ & $-0.15 \dagger$ \\
\hline $\begin{array}{l}\text { Chronic } \\
\text { Job Insecurity }\end{array}$ & & & & $-0.29 * *$ \\
\hline$R^{2}$ & 0.40 & 0.43 & 0.43 & 0.46 \\
\hline
\end{tabular}

Table entries are standardized regression coefficients.

${ }^{b}$ Dummy variable coded $1=$ Black, $0=$ Other.

'Dummy variable coded $1=$ Hourly, $0=$ Salaried

$+P<0.01,{ }^{*} P<0.05,{ }^{* *} P<0.01,{ }^{* * *} P<0.001$.

of job insecurity and a chronically high level at both Time 1 and 2 were predictive of decreases in job satisfaction. For physical health, however, a chronic high level of job insecurity was the best predictor of increases in symptomatology.

The demographics of our sample are similar to those in larger representative samples of manufacturing workers $[13,21]$. In addition, the cross-sectional relationships found between various job stressors and health measures using this data set have replicated the relationships found throughout the occupational stress literature [5]. Thus, it would appear that the relationship of chronic job insecurity to job satisfaction and physical symptoms would not be systematically different in our sample than it would be for manufacturing employees as a whole. Nevertheless, this study involves only a single organization and a self-selected sample, and thus similar studies should be conducted using larger, representative samples of manufacturing workers.

Generalizability of these findings may also be limited to workers who have been stably employed by one company for a long time. The employees in this study had worked for this company for an average of almost 20 years. Losing their jobs would mean separation from the work setting that was their primary place of employment through their adult lives. In addition, for these employees, job insecurity stems from market forces, not personal incompetence. Employees who blame themselves for their job insecurity may experience different effects than those described here. Lastly, for employees in this study, it would be difficult to find a new job that would match the wage and benefit package of their current jobs. Thus, job insecurity may take a greater toll on these employees than it would on employees who could easily find jobs comparable to those they lost.

Another possible limitation is the self-report nature of the physical symptomatology measure. Self-report health measures, as well as perceived stress measures, may reflect a common tendency toward negative affectivity [22], thus inflating the association between stress and ill health. The importance of negative affectivity as a confounder in stress research is currently being hotly debated, and empirical evidence has been inconsistent $[23,24]$. For this study, it is interesting to note that chronic high job insecurity was not related to Time 2 depres-

Table 4. Heirarchical regression models of the effects of job insecurity on Time 2 physical symptomatology

\begin{tabular}{lcccc}
\hline Independent & Step & Step & Step & Step \\
variables & 1 & 2 & 3 & 4 \\
\hline Age & -0.01 & 0.01 & 0.02 & 0.02 \\
Education & 0.02 & 0.04 & 0.03 & 0.00 \\
Raceb & 0.04 & 0.02 & 0.02 & 0.03 \\
$\begin{array}{l}\text { Job class } \\
\text { Time 1 } \\
\quad \text { Physical Symptoms }\end{array}$ & $0.09 \dagger$ & 0.04 & 0.03 & 0.02 \\
$\begin{array}{l}\text { Time 1 } \\
\quad \text { Job Insecurity }\end{array}$ & $0.78^{* * *}$ & $0.75^{* * *}$ & $0.76^{* * *}$ & $0.75^{* * *}$ \\
$\begin{array}{l}\text { Time 2 } \\
\quad \text { Job Insecurity }\end{array}$ & & $0.14^{* *}$ & 0.09 & 0.03 \\
$\begin{array}{l}\text { Chronic } \\
\text { Job Insecurity }\end{array}$ & & & 0.08 & -0.04 \\
$R^{2}$ & 0.64 & 0.66 & 0.66 & $0.19 * *$ \\
\hline
\end{tabular}

Table entries are standardized regression coefficients.

Dummy variable coded $1=$ Black, $0=$ Other.

${ }^{\mathrm{C}}$ Dummy variable coded $1=$ Hourly, $0=$ Salaried

$\dagger P<0.10, * * P<0.01, * * P<0.001$. 
sive symptoms. Depressive symptoms is a measure that one would expect to be highly associated with negative affectivity. This suggests that negative affectivity does not account for our results.

Even though it is difficult to assess the clinical significance of an increase in self-reported physical symptoms, this measure has some advantages over other possible physical health measures. This index covers a wide spectrum of possible health complaints, many of which can only be measured through selfreport (e.g. persistent back pain, frequent headaches and extreme fatigue). The broad range of symptoms included in this measure is quite appropriate given the non-specific role of psychosocial stress in the etiology of illness $[6,25]$. In addition, physical symptom inventories have been shown to correlate with important worksite outcomes such as abenteeism [26] and job performance [27].

The duration of this study is limited to a time period of 14 months. In-depth interviews with a subset of study participants portrayed job insecurity as a major stressor in this plant for the past ten years. Thus, this study does not shed light on how long job insecurity must be experienced in order for effects due to chronicity to occur. Also, since job satisfaction and physical symptoms may have already been affected by chronic job insecurity at the start of the study, the size of the effects of chronic job insecurity may be underestimated.

The implications of the present study for future research are twofold. First, our results illustrate that job insecurity acts as a potent chronic stressor and should be included in studies of occupational stress, particularly in industries where employment opportunities are declining. Second, this study demonstrates the need to conduct longitudinal studies of stress in which measures of stress, job satisfaction and health are taken at multiple points in time. Only through the careful design and implementation of such studies will the time frame for the unfolding of the stress process in response to particular stressors be identified. Important effects of stress on health may be underestimated due to an inappropriate data collection time frame.

Our results also have implications for public health practice. Increasing automation, shorter product cycles, relocation of factories and continued competition in the marketplace all suggest that job security will remain low for many American workers in the manufacturing sector. Given that the present study suggests that the negative effects of job insecurity will increase over time, worksite health professionals should develop strategies for reducing the impact of job insecurity on employee well-being. For example, health professionals can:

(1) attempt to enhance accurate informationgiving and communication so as to reduce unnecessary uncertainty $[9,28]$;

(2) advocate for organizational policies that provide for the retraining of employees so that they have viable employment alternatives when terminated from their current positions;

(3) engage in efforts aimed at creating income security protection policies which provide for some specified time period during which employees are guaranteed not to be terminated from their jobs, but rather to continue to receive their income by being assigned to a jobs bank to carry out tasks as needed; and

(4) provide training to employees in how to cope with the stress engendered by job insecurity.

In addition, given not only the results of this study but also the extensive research that associates unemployment with poor health [29], health professionals and their professional associations should support policy initiatives at the national, state and local levels for ensuring employment opportunities in the manufacturing sector.

Acknowledgements - This study was supported in part by Grant no. 501AA06553 from the National Institute of Alcohol Abuse and Alcoholism. The project is presently funded by joint funds from the UAW/GM National Joint Committee on Health and Safety. The authors thank Sue Schurman for her comments on an earlier draft of this paper.

\section{REFERENCES}

1. Karasek R. and Theorell T. Healthy Work. Basic Books, New York, 1990.

2. Fletcher B. The epidemiology of occupational stress. In Causes, Coping and Consequences of Stress at Work (Edited by Cooper C. L. and Payne R.), pp. 3-52. John Wiley, Chichester, 1988.

3. Holt, R. R. Occupational stress. In Handbook of Stress (Edited by Goldberger L. and Breznitz S.), pp. 419-444. The Free Press, New York, 1982.

4. House J. S., Wells J. A., Landerman L. R., McMichael A. J. and Kaplan B. H. Occupational stress and health among factory workers. $J$, Hlth Soc. Behav. 20 , 139-160, 1979.

5. Israel B. A., House J. S., Schurman S. J., Heaney C. A and Mero $R$. P. The relation of personal resources, participation, influence, interpersonal relationships and coping strategies to occupational stress, job strains and health: a multivariate analysis. Work Stress. 3, 163-194, 1989.

6. Kiecolt-Glaser J. K. and Glaser R. Psychological influences on immunity: making sense of the relationship between stressful life events and health. Adv. Exp. Med. Biol. 245, 237-247, 1988.

7. Shilling S. and Brackbill R. M. Occupational health and safety risks and potential health consequences perceived by US workers. Public Health Rep. 102, 36-46, 1987.

8. National Institute of Occupational Safety and Health Occupational Safety and Health Status FY 1986. NIOSH, Cincinnati, OH, 1987.

9. Sutton R. and Kahn R. L. Prediction, understanding, and control as antidotes to organizational stress. In Handbook of Organizational Behaviour (Edited by Lorsch J.), pp. 272-285. Prentice Hall, Englewood Cliffs, NJ, 1987.

10. Van Sell M. Brief A. P. and Schuler R. S. Role conflict and role ambiguity: integration of the literature and 
directions for future research. Human Relations 34, 43-72, 1987.

11. Joelson L. and Wahlquist L. The psychological meaning of job insecurity and job loss: results of a longitudinal study. Soc. Sci. Med. 25, 179-182, 1987.

12. Vance R. J. and Kuhnert K. W. Job and employment security and security valence: interactive effects on employment adjustment. Paper presented at the Annual Convention of the American Psychological Association, 1989.

13. Caplan R. D., Cobb S., French J. R. P., Van Harrison R. and Pinneau S. R. Job Demands and Worker Health. NIOSH, Cincinnati, OH, 1975.

14. Mattiasson I., Lindgarde F., Nilsson J. A. and Theorell T. Threat of unemployment and cardiovascular risk factors: longitudinal study of quality of sleep and serum cholesterol concentrations in men threatened with redundancy. $B r . M e d . J .301,461-466$, 1990.

15. Owens A. C. Sick leave among railwaymen threatened by redundancy: a pilot study. Occ. Psych. 40, 43-52, 1966.

16. Jenkins, R., MacDonald A., Murray J. and Strathdee G. Minor psychiatric morbidity and the threat of redundancy in a professional group. Psych. Med. 12, 799-807, 1982.

17. Kasl S. V., Gore S. and Cobb S. The experience of losing a job: reported changes in health, symptoms, and illness behavior. Psychosom. Med. 37, 106-122, 1975.

18. Lazarus R. S. Psychological Stress and the Coping Process. McGraw Hill, New York, 1966.

19. House J. S., Strecher V., Metzner H. L. and Robbins C.
Occupational stress and health among men and women in the Tecumseh Community Health Study. J. Hlth Soc. Behav. 27, 62-77, 1986.

20. Arnetz B. B., Brenner S., Levi L. et al. Neuroendocrine and immunological effects of unemployment and job insecurity. Psychother. Psychosom. 55, 76-80, 1991.

21. Loscocco K. A. and Spitze G. Working conditions, social support, and the well-being of female and male factory workers. J. Hlth Soc. Behav. 31, 313-327, 1990.

22. Watson D. and Pennebaker J. W. Health complaints, stress, and distress: exploring the central role of negative affectivity. Psych. Rev. 96, 234-254, 1989.

23. Chen P. Y. and Spector P. E. Negative affectivity as the underlying cause of correlations between stressors and strains. J. appl. Psych. 76, 398-407, 1991.

24. Brief A. P., Burke M. J., George J. M., Robinson B. S. and Webster J. Should negative affectivity remain an unmeasured variable in the study of job stress? J. appl. Psych. 73, 193-198, 1985.

25. Cassel $\mathbf{J}$. The contribution of the social environment to host resistance. Am. J. Epid. 14, 107-123, 1976.

26. Kristensen T. S. Sickness absence and work strain among Danish slaughterhouse workers: an analysis of absence from work regarded as coping behavior. Soc. Sci. Med. 32, 15-27, 1991.

27. Ivancevich J. M. Life events and hassles as predictors of health symptoms, job performance, and absenteeism. $J$. Occ. Behav. 7, 39-51, 1986.

28. Price R. H. and D'Aunno T. Managing work force reduction. Hum. Resource Mgmt 22, 413-430, 1983.

29. Levi L. (Ed.) Unemployment and health. Soc. Sci. Med. 25(2) special issue, 1987. 